\title{
Erratum to: Synthesis, antimicrobial activity and docking studies of new $\mathrm{N}$-ethyl-3-indolyl heterocycles
}

\author{
Wael A. El-Sayed ${ }^{1} \cdot$ Hebat-Allah S. Abbas ${ }^{1,2} \cdot$ Randa E. Abdel Magid $^{1} \cdot$ Tomasz Magdziarz $^{3}$
}

Published online: 28 January 2016

(c) Springer Science+Business Media New York 2016

Erratum to: Med Chem Res (2016) 25:339-355

DOI 10.1007/s00044-015-1488-4

The original version of this article unfortunately contained a mistake. The first author's name was incorrectly spelled as "Weal A. El-Sayed"; it should be "Wael A. El-Sayed." The author name is corrected through this erratum.

The online version of the original article can be found under doi:10.1007/s00044-015-1488-4.

Hebat-Allah S. Abbas

hebanrc@yahoo.com

1 Photochemistry Department, National Research Centre, 12622 Dokki, Giza, Egypt

2 Chemistry Department, College of Science, King Khalid University, Abha, Saudi Arabia

3 Molecular Networks GmbH - Computerchemie, Henke-str. 91, 91052 Erlangen, Germany 